\title{
Microbial diversity in soils from antimony mining sites: geochemical control promotes species enrichment
}

\author{
Renjian Deng ${ }^{1,2} \cdot$ Zhie Tang $^{1} \cdot$ Baolin Hou ${ }^{1} \cdot$ Bozhi Ren ${ }^{1} \cdot$ Zhenghua Wang $^{1} \cdot$ Chuanqu Zhu ${ }^{3}$. Steven Kelly ${ }^{4}$. \\ Andrew Hursthouse ${ }^{1,5}$
}

Received: 18 March 2019 / Accepted: 7 February 2020 / Published online: 24 February 2020

(c) The Author(s) 2020

\begin{abstract}
Elevated soil concentrations of antimony $(\mathrm{Sb})$ and co-contaminants are frequently encountered where antimony has been mined on a large scale. For instance, the Xikuangshan antimony mine in central South China has sustained, over many centuries, dispersed and spatially variable input of toxic elements into the soil ecosystem. We utilized this unique environment to assess the impact of geochemical conditions on soil microbiology. Geochemical conditions were assessed by monitoring absolute and available fractions of toxic elements and disrupted soil properties. Soil microbiology was studied by high-throughput sequencing and statistical analysis, including principle component analysis and canonical correspondence analysis. Results show that $\mathrm{Sb}$ concentrations were ranged from 970 to more than $24,000 \mathrm{mg} / \mathrm{kg}$. As concentrations were three times higher than the regional background values and ten times higher for $\mathrm{Pb}, 590$ times higher for $\mathrm{Cd}$ and 30 times higher for $\mathrm{Hg}$. About $5-10 \%$ of the total soil Sb was environmentally mobile. Microbial diversity was high, and soil properties such as $\mathrm{pH}$, organic matter, iron and sulfate controlled the absolute microbial activity. We identified strong positive and negative correlations with specific bacterial taxonomic groups which show: (1) an intolerance of available fractions for all elements, e.g., Gemmatimonas, Pirellula, Spartobacteria; (2) a good tolerance of available fractions for all elements, e.g., Povalibacter, Spartobacteria; and (3) a mixed response, tolerating available $\mathrm{Sb}, \mathrm{Hg}$ and $\mathrm{Cd}$ and inhibition by $\mathrm{As}, \mathrm{Pb}$, e.g., Escherichia/Shigella and Arthrobacter, and in reverse, e.g., Gemmatimonas and Sphingomonas. The site hosts great diversity dominated by Gram-negative organisms, many with rod (bacillus) morphologies but also some filamentous forms, and a wide range of metabolic capabilities: anaerobes, e.g., Saccharibacteria, metal oxidizing, e.g., Geobacter, chemoautotrophs, e.g., Gemmata, and sulfur reducing, e.g., Desulfuromonas. The bioremediation potential of Arthrobacter and Escherichia/ Shigella for $\mathrm{Sb}$ control is highlighted.
\end{abstract}

Keywords Potentially toxic element (PTE) contamination · Antimony mine $\cdot$ Soil microbial population structure $\cdot$ Highthroughput sequencing $\cdot$ Canonical correspondence analysis $(\mathrm{CCA})$

Electronic supplementary material The online version of this article (https://doi.org/10.1007/s10311-020-00975-1) contains supplementary material, which is available to authorized users.

Andrew Hursthouse

Andrew.hursthouse@uws.ac.uk

1 School of Civil Engineering, Hunan University of Science and Technology, Xiangtan 411201, China

2 Hunan Jing Yi Environmental Protection High Tech Development Co. Ltd, Xiangtan 411100, China

3 School of Resource Environment and Safety Engineering, Hunan University of Science and Technology, Xiangtan 411201, China
4 School of Health and Life Sciences, University of the West of Scotland, Hamilton G72 0LH, UK

5 School of Computing, Engineering and Physical Sciences, University of the West of Scotland, Paisley PA1 2BE, UK 


\section{Introduction}

Antimony ( $\mathrm{Sb}$ ) is a naturally occurring metalloid capable of forming toxic products, is a suspected carcinogen (Gebel 1997; ATSDR 2019) and has been classed as a priority substance (ATSDR, 2017). Antimony can be enriched in soils as a result of the mobilization of antimony from minerals and waste antimony ore and activities including mining, mineral smelting and the use of drugs and pesticides (Okkenhaug et al. 2016; Wang et al. 2011), allowing interaction with the wider hydrological, biological and surface environment (Filella et al. 2007). In addition, $\mathrm{Sb}, \mathrm{As}, \mathrm{Pb}, \mathrm{Cd}$ and $\mathrm{Hg}$ frequently coexist in antimony ore deposits (Terry et al. 2015) and the mining of Sb can cause the release of significant amounts of coexisting elements enhancing the potential hazard of the location. For $\mathrm{Sb}$, the toxicity of environmental species varies with $\mathrm{Sb}$ (III) of highest potential toxicity compared to $\mathrm{Sb}(\mathrm{V})$; consequently, inorganic forms are of greatest interest (Guo et al. 2018).

A number of examples of mining locations of interest include on the Mediterranean coast in the Marseille region of France, the Hillgrove $\mathrm{Sb}-\mathrm{Au}$ mine in New South Wales, Australia, and the Xikuangshan (XKS) Sb mine in Hunan, China, which have all been linked to the release of significant amounts of co-occurring toxic elements impacting on the local environment (Okkenhaug et al. 2016; Telford et al. 2009), with limited understanding of wider impact of co-contamination with toxic elements (Gebel 1997) (Xiao et al. 2017).

Despite the toxicity of associated elements, many indigenous microorganisms can survive and thrive in soils and contaminated waters. Microbial enhanced migration as well as geochemical transformation of elements can encourage the precipitation and immobilization, contributing to the remediation strategy to deal with contaminated soils and waters (Ungureanu et al. 2015; Escudero et al. 2019). Microbial cycling is primarily achieved by reduction, oxidation and methylation among other processes (Magalhaes et al. 2015). With the aid of PCR-DGGE, it has been shown that $\mathrm{Pb}$ and $\mathrm{Cd}$ contamination can have a significant influence on the microbial community structure present in soil systems. It is also reported that the concentration of $\mathrm{Sb}$ in the environment is an important factor affecting the resistance of bacteria to $\mathrm{Sb}$ (III) (Shi et al. 2013). Luo et al.(2014) adopted qPCR to elucidate the expression of microbial genes in environments highly contaminated with $\mathrm{Sb}$ and As (Luo et al. 2014). They found that abundance of functional genes (e.g., ars $C$ and aioA), diversity index and microbial population structure related to the metabolic circulation of $\mathrm{As}$ and $\mathrm{Sb}$ were positively correlated with the concentrations of As and
$\mathrm{Sb}$ in soils (Luo et al. 2014). Recently, using Illumina sequencing of $16 \mathrm{~S}$ rRNA, studies reported the investigation of the correlation between microbial community profiles and concentrations of $\mathrm{Sb}$ and $\mathrm{As}$ in soils and water (Sun et al. 2016a, b; Xiao et al. 2016, 2017). Recent work also includes the use of metagenomics and metagenomic binning to investigate the soil microflora response to As and $\mathrm{Sb}$ contamination, providing progresses using state-ofthe-art molecular tools to unravel the interactions between microbiota and Sb and As (Sun et al. 2018; Sun et al. 2017). Significant positive correlation was demonstrated between groups and the extractable fractions of $\mathrm{Sb}$ and $\mathrm{As}$ in soils (Sun et al. 2016a, b; Xiao et al. 2016, 2017). In addition, a large number of bacterial genera were found in Sb-rich and As-rich mine soil, including Flavobacterium, Sulfuricurvum, Halomonas, Shewanella, Lactobacillus and Geobacter (Sun et al. 2016a), suggesting widespread tolerance to $\mathrm{Sb}$ and As exposure, if not utilization. The elements $\mathrm{Sb}$ and As have similar chemical behavior and toxicity and frequently co-occur (Terry et al. 2015), but our current knowledge of the genetics and biochemistry of biological transformation of $\mathrm{Sb}$ is still limited compared to the extensive studies on microbial cycling of As (Filella et al. 2007). A better understanding is required of microbial community structure variation in response to the presence of $\mathrm{Sb}$ and associated elements and more significantly their distribution between strongly, partially and non-mobile fractions in the contaminated soil system (Chen et al. 2007).

The XKS Sb mine, considered to be the largest antimony mine in the world (He et al. 2012), is located in Hunan Province, central South China, and provides a unique location to study the interrelation between microbial populations and a range of concentrations of $\mathrm{Sb}$ and associated elements in soil developed across the area. Centuries of mining and ore processing have resulted in extensive contamination by $\mathrm{Sb}, \mathrm{As}, \mathrm{Pb}, \mathrm{Cd}$ and $\mathrm{Hg}$, with $\mathrm{Sb}$ concentrations reaching $527-11,798 \mathrm{mg} / \mathrm{kg}$ in soil (Okkenhaug et al. 2011; Guo et al. 2014, 2018). To develop effective bioremediation strategies for these disrupted systems, we need to learn more about the influence of element geochemistry on the composition of the microbial community and the metabolic functions of the indigenous microorganisms. Using a combination of molecular, biological and geochemical analytical methods, we studied the microbial population structure in response to soil contamination. Specifically, the objectives were to: (1) analyze dynamics of the community composition and structure of microorganism to cope with different geochemical fractions of toxic elements and (2) to investigate their interrelation to reveal the most important microbial and geochemical controls. 


\section{Materials and methods}

\section{Study area and sample collection}

Field work was carried out in April 2018 with eight bulk samples taken from surface soils in the XKS mining area for the combined geochemical and microbial community analysis (Fig. 1). Detailed description of the site location and regional context is given elsewhere (Guo et al. 2018). Sample locations are identified as NK1 $\sim$ NK4 and SK1 SK4. Location NK1 is in the north, near the active antimony smelting area, and NK2-NK4 are between the south mine and north mine, with a separation of about $800 \mathrm{~m}$; SK1 is in the south close to a lead and zinc smelting area abandoned 2 years before sampling took place, SK2 is near the southern smelter, and SK3 and SK4 are located near a deposit of smelter slag, about $500 \mathrm{~m}$ downstream of the mine tailings. A composite sample was collected at each site from surface soil (to 5-10 cm depth) in a widemouthed container (1 kg bulk soil collected). All samples were immediately transferred to sterile plastic bottles and stored in freezers $\left(-20^{\circ} \mathrm{C}\right)$ pending further analysis.

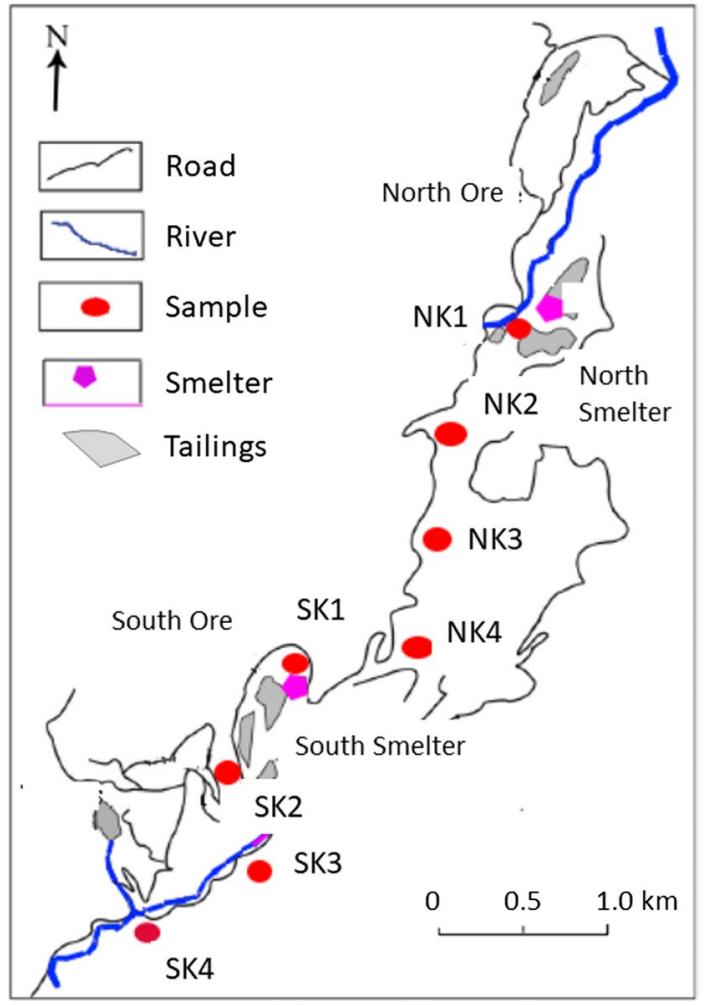

Fig. 1 Sketch map of the sampling locations at the Xikuangshan (XKS) site, Hunan Province, China (see Guo et al. 2018 for detailed regional context). Site plan shows locations of major ore processing (smelter) and waste (tailings) locations (shaded patches) in relation to samples collected in the study

\section{Geochemical parameters and analytical methods}

Subsamples of soil were air-dried until constant weight, and the $\mathrm{pH}$ and anion concentrations in the soil samples were measured using the methods in Xiao et al. (2016). The soil $\mathrm{pH}$ was measured using a HACH HQ440d pH meter. Anions in the filtered water extracts were determined with ion chromatography (ICS-90A, Dionex, USA). Total carbon, total nitrogen, total sulfur (to give $\mathrm{SO}_{4}^{-}$) and chloride $\left(\mathrm{Cl}^{-}\right)$in soil samples were determined by PE-240C elemental analyzer (Perkin Elmer, USA) (Xiao et al. 2016). A subsample was ground using a mortar and pestle, then sieved using a 100-mesh screen, subsequently digested with hydrofluoric acid and nitric acid $(5: 1 \mathrm{v} / \mathrm{v})$ to provide a clear solution (Xiao et al. 2016) and filtered; then, target elements (Sb, $\mathrm{As}, \mathrm{Pb}, \mathrm{Cd}, \mathrm{Hg}$ ) were measured using a double-channel atomic fluorescence spectrometer (AFS-9700, Beijing Hai Guang Instrument Co., Ltd., China) and atomic absorption spectrophotometer (AA-7002A, EWAI, China). All samples were measured in triplicate with matrix-matched standards. Internationally certified reference materials (SLRS-5 Canadian River water) and internal standards ( $\mathrm{Rh}$ at $500 \mathrm{mg} / \mathrm{L}$ ) were used for accuracy of analysis with GBW07310 (stream sediment) of Chinese National Standard that was used for analytical quality control (Xiao et al. 2016) with excellent recoveries achieved $( \pm 1.7-8.0 \%)$ (Table $\mathrm{S} 1)$.

\section{Sequential chemical extraction}

The association of the toxic elements in the air-dried soil was tested using a five-stage sequential chemical extraction method based on Tessier and applied to samples collected on site and a second method modified for As and $\mathrm{Sb}$ (Wenzel et al. 2001), (Tessier et al. 1979). Although there is considerable discussion surrounding direct correlation with molecular speciation in soils (Bacon and Davidson 2008), these extraction schemes have been widely applied to provide evaluation as indicators of relative elemental (bio)availability (Lee and Yu 2016; Wei et al. 2010) under similar conditions elsewhere (Gal et al. 2006). A $1 \mathrm{~g}$ aliquot of each soil (with replicates) was placed in separate plastic tubes and subject to extraction (Table S2). All equipment was presoaked and washed by dilute acid. All extractions were conducted in 50-mL centrifuge tubes at room temperature of $25^{\circ} \mathrm{C}$, and they were shaken at $250 \mathrm{r} / \mathrm{min}$. After each step of the extraction, the solution was centrifuged at $3500 \mathrm{r} / \mathrm{min}$ for $20 \mathrm{~min}$ and then the supernatant analyzed by ICP-OES (Shimadzu, ICPS-7500, Japan) after appropriate dilution. For the purpose of this study, the extraction data were grouped into three categories: available (exchangeable-F1); poorly available (carbonate $+\mathrm{Fe}-\mathrm{Mn}$ oxides + organic-F2 $+\mathrm{F} 3+\mathrm{F} 4)$; inert (residual-F5) (Flynn et al. 2003; Xiao et al. 2016) (Buanuam and Wennrich 2010; Chen et al. 2007). All 
sequential chemical extraction experiments (including modified Tessier for $\mathrm{As} / \mathrm{Sb}$ ) were performed in triplicate, and summed totals of individual extraction fractions agreed extremely well $(< \pm 10 \%)$ with independent total element content (Table S3).

\section{S rRNA high-throughput sequencing of the V3-V4}

Total genome DNA was extracted from $10 \mu \mathrm{g}$ of DNA samples using the EZNA ${ }^{\text {TM }}$ Mag-Bind Soil DNA Kit (Omega, M5635-02). All extracted DNA was preserved at $-80^{\circ} \mathrm{C}$ until further testing. Both purity of $1 \%$ agarose gel and DNA concentration were measured and monitored. To analyze the microbial community, 16S rRNA genes in the V3-V4 region were expanded by the primers of $341 \mathrm{~F}$ and $805 \mathrm{R}$ (Park et al. 2018). Ultra-high-throughput sequencing of 16S rRNA genes was performed on the Miseq $2 \times 400 \mathrm{bp}$ platform at Sangon Biotech (Shanghai, China). Sequencing analysis was carried out using QIIME software (version 1.8.0) (Caporaso et al. 2010). Paired-end reads were combined using FLASH software (version 1.2.3). By truncating the barcode and primer sequences, the combined reads were assigned to the samples.

The raw reads were filtered using QIIME software (version 1.8.0) with the criteria previously described (Caporaso et al. 2010). In order to discover and delete chimera sequences, all the tags were compared with Gold database using UCHIME software (version 4.2.40). The operational taxonomic units (OTUs) at similarity of $97 \%$ were clustered using "usearch" software (OmicX, version 5.2.236), and taxonomy of all samples was assigned by the RDP classifier (OMICS_18112, version 2.12) (Quast et al. 2013; Wang et al. 2007). The community richness and diversity for the eight libraries were calculated by Chao 1 and Shannon indices (Schloss et al. 2009).

\section{Data analysis}

Both of the weighted and non-weighted UniFrac methods were used to analyze the similarity of microbial populations in different soil samples (Xiao et al. 2016). Beta diversity and richness were visualized through the use of Mothur software (version 1.30.1) (Schloss et al. 2009), and Circos plots were produced on the Web site (http://circos.ca/).

All significance tests were two-tailed and $p<0.05$, which indicated that the difference is statistically significant. In order to choose the main geochemical parameters which had significant impact on community structure of microorganisms, the canonical correspondence analysis (CCA) (version CANOCO 4.5) was adopted in this study (Sun et al. 2016a, b; Xiao et al. 2017). The CCA was performed for the enriched genus with a relative abundance of more than $1 \%$ in at least one sequencing library. Then, the significance of environmental variables was chosen using 999 artificial forward selections of Monte Carlo displacement tests (Lepš and Šmilauer 2003). The multivariate method of CCA can directly correlate geochemical parameters with genus abundance. The position of symbol relative to the vector head implies the relationship between the environmental variables and the microbial profile, and the length of the vector reflects the degree of significance of the geochemical parameters in discerning the total microbial population in a library (Xiao et al. 2016; Shi et al. 2013). The CCA was performed for interspecies differences, and the correlation between geochemical parameters and relative abundance of primary genus was determined using the SPSS (version 19). Except where highlighted, $p<0.05$ indicated a significant correlation. Since the rank correlation coefficient of Spearman is a nonparametric method, no null hypothesis is required for the original data (Xiao et al. 2016). In at least one library, only the relative abundance of genus exceeded $1 \%$ of the total genus, and the main geochemical parameters of interest were selected for analysis in this study.

\section{Results and discussion}

\section{Spatial distribution of $\mathrm{Sb}$ and associated elements in XKS soils}

The distribution of total concentrations of $\mathrm{Sb}$ and associated elements $(\mathrm{As}, \mathrm{Pb}, \mathrm{Cd}$ and $\mathrm{Hg}$ ) in the soil samples, and the absolute availability in extraction fractions are shown in Table 1. The $\mathrm{Sb}_{\text {tot }}$ ranged from -970 (SK4) to $>24,000 \mathrm{mg} /$ $\mathrm{kg}$ (NK1), with a mean $\mathrm{Sb}_{\text {tot }}$ concentration of $5426 \mathrm{mg} / \mathrm{kg}$. The available $\mathrm{Sb}\left(\mathrm{Sb}_{\text {avail }}\right)$ varied from - 20 (SK4) to $200 \mathrm{mg}$ / $\mathrm{kg}$ (NK1). The poorly available $\mathrm{Sb}\left(\mathrm{Sb}_{\text {pavailo }}\right)$ fraction accounted for between 19\% (SK3) and 34\% (NK1) of $\mathrm{Sb}_{\text {tot }}$, ranging from 246 (SK3) to $1890 \mathrm{mg} / \mathrm{kg}$ (NK1). The portion of the $\mathrm{Sb}_{\text {avail }}$ was higher in the North ore (6.26-10.56\%) than in the South ore (4.54-6.47\%) samples. Although the portion of $\mathrm{Sb}_{\text {pavail }}$ was between $\sim 22 \%$ and $34 \%$, the result is lower than that of previous findings (Xiao et al. 2016) and may reflect effects of weathering in the surface soils. However, the absolute amounts of the $\mathrm{Sb}_{\text {avail }}$ and $\mathrm{Sb}_{\text {pavail }}$ ranged from 229.30 to $>8380 \mathrm{mg} / \mathrm{kg}$, reflecting a strong potential ecological risk for soils in the study area (Buanuam and Wennrich 2010). The soils close to the XKS smelter, especially at SK1, SK4 and SK2, are particularly contaminated, and the average concentration ( $>5400 \mathrm{mg} / \mathrm{kg}$ ) of all samples is magnitudes higher than the Hunan Province Chinese background value $(2.98 \mathrm{mg} / \mathrm{kg})$, but agrees with results of work by others in the area (Mo et al. 2013; Okkenhaug et al. 2011). These levels are also much higher observed at other $\mathrm{Sb}$ ore and processing zones which are considered to be seriously polluted, including the $\mathrm{Sb}$ smelter in northeastern 
Table 1 Absolute concentrations $(\mathrm{mg} / \mathrm{kg})$ for three levels of availability of toxic elements in soil samples from the XKS study area. $\mathrm{M}_{\mathrm{tot}}=$ total sample concentration; $\mathrm{M}_{\text {avail }}=$ available (F1); $\mathrm{M}_{\text {pavail }}=$ poorly available (F2 + F3 + F4) (see Tables S3 and $\mathrm{S} 4$ for analytical details)

\begin{tabular}{|c|c|c|c|c|c|c|c|c|}
\hline Sample & NK1 & NK2 & NK3 & NK4 & SK1 & SK2 & SK3 & SK4 \\
\hline $\mathrm{Sb}_{\text {tot }}$ & 24,345 & 2066 & 1269 & 6192 & 5152 & 2170 & 1244 & 972 \\
\hline $\mathrm{Sb}_{\text {avail }}$ & 199 & 28.3 & 23.4 & 133 & 56.2 & 45.1 & 34.1 & 20.2 \\
\hline $\mathrm{Sb}_{\text {pavailo }}$ & 8185 & 494 & 415 & 1892 & 1022 & 623 & 246 & 279 \\
\hline $\mathrm{As}_{\mathrm{tot}}$ & 26.7 & 50.0 & 34.8 & 47.9 & 31.2 & 36.3 & 89.3 & 46.7 \\
\hline $\mathrm{As}_{\text {avail }}$ & 0.15 & 0.16 & 0.15 & 0.23 & 0.12 & 0.10 & 0.38 & 0.13 \\
\hline $\mathrm{As}_{\text {pavailo }}$ & 1.80 & 3.33 & 7.79 & 2.83 & 9.77 & 5.34 & 10.15 & 6.86 \\
\hline $\mathrm{Pb}_{\text {tot }}$ & 198 & 105 & 44.6 & 474 & 777 & 391 & 130 & 202 \\
\hline $\mathrm{Pb}_{\text {avail }}$ & 4.76 & 1.03 & 0.58 & 8.67 & 1.48 & 4.18 & 1.89 & 2.17 \\
\hline $\mathrm{Pb}_{\text {pavial }}$ & 21.7 & 18.3 & 4.8 & 36.1 & 102 & 16.1 & 22.2 & 8.32 \\
\hline $\mathrm{Cd}_{\mathrm{tot}}$ & 17.4 & 27.3 & 15.4 & 53.1 & 130 & 46.7 & 46.4 & 40.1 \\
\hline $\mathrm{Cd}_{\text {avail }}$ & 0.23 & 0.26 & 0.07 & 0.54 & 1.00 & 0.66 & 0.77 & 0.57 \\
\hline $\mathrm{Cd}_{\text {pavail }}$ & 4.05 & 5.11 & 6.29 & 7.58 & 20.9 & 15.2 & 18.4 & 13.0 \\
\hline $\mathrm{Hg}_{\text {tot }}$ & 4.62 & 3.51 & 2.87 & 3.69 & 3.89 & 2.17 & 2.59 & 3.27 \\
\hline $\mathrm{Hg}_{\text {avail }}$ & 0.15 & 0.14 & 0.04 & 0.08 & 0.14 & 0.05 & 0.13 & 0.08 \\
\hline $\mathrm{Hg}_{\text {pavail }}$ & 0.52 & 0.75 & 0.79 & 0.48 & 0.67 & 0.56 & 0.83 & 0.84 \\
\hline $\mathrm{pH}$ & 7.25 & 6.14 & 6.45 & 6.91 & 7.71 & 6.54 & 6.88 & 7.15 \\
\hline Total N (mg/kg) & 2630 & 72 & 40.3 & 1320 & 1820 & 620 & 500 & 53 \\
\hline Total C (mg/kg) & 46,800 & 40,340 & 32,960 & 48,720 & 63,260 & 42,680 & 31,240 & 34,240 \\
\hline Total Fe (g/kg) & 56.0 & 18.8 & 31.7 & 28.4 & 38.1 & 21.4 & 32.8 & 26.7 \\
\hline Chloride (mg/kg) & 14.2 & 14.2 & 85.2 & 7.1 & 14.2 & 7.1 & 14.2 & 7.1 \\
\hline Sulfate $(\mathrm{mg} / \mathrm{kg})$ & 20.07 & 139.96 & 109.09 & 365.03 & 114.27 & 704.42 & 224.61 & 16.28 \\
\hline
\end{tabular}

England ( 1500-5000 mg/kg) (Ainsworth et al. 1990), the Yata Au mine (1163 mg/kg) (He et al. 2012), and the majority of locations at an abandoned antimony ore area in Italy $(27->15,000 \mathrm{mg} / \mathrm{kg})$. In NK1, NK4 and SK1, the $\mathrm{Sb}_{\text {tot }}$ was much higher than other locations due to their proximity to the smelter. Preliminary data confirm that stack emission is the main source of local pollution (Mo et al. 2013; Okkenhaug et al. 2011). In addition, while the $\mathrm{Sb}_{\text {tot }}$ decreased with increasing distance from the smelter, the portion of $\mathrm{Sb}_{\text {avail }}$ increased showing increased environmental availability but proportionally low compared to data from other environments (Flynn et al. 2003; Ollson et al. 2017; Xiao et al. 2016) and reflects aging/weathering of the surface-oxidized layers of the site.

The concentrations of $\mathrm{As}, \mathrm{Pb}, \mathrm{Cd}, \mathrm{Hg}$ and their available fractions are summarized in Table 1. The mean $\mathrm{As}_{\text {tot }}$, $\mathrm{Pb}_{\text {tot }}, \mathrm{Cd}_{\text {tot }}$ and $\mathrm{Hg}_{\text {tot }}$ concentrations in the soil samples were $45.37,290.26,47.08$ and $2.71 \mathrm{mg} / \mathrm{kg}$, respectively, representing 3.2, 10.8, 595.9 and 30.1 times the Hunan Provincial background value (Pan and Yang 1988). The results confirm the significance of the co-contamination levels for $\mathrm{As}, \mathrm{Pb}$, $\mathrm{Cd}$ and $\mathrm{Hg}$. In addition, the available fractions of these elements were also relatively low. In this study, both $\mathrm{Cd}$ and $\mathrm{Hg}$ are more significant pollutants than As, which is unusual for $\mathrm{Sb}$ mines and other industrially contaminated locations (Okkenhaug et al. 2011; Xiao et al. 2017) despite its significant abundance in the primary ore deposit. This may be the result of the specific smelter processes taking place at this location (Guo et al. 2014) and differences in the mineralogical association ( $\mathrm{Sb}$ as mixed oxides/sulfides, while other associations predominantly with sulfide phases). The physical and chemical parameters of the soil samples are also summarized in Table 1 . The soil $\mathrm{pH}$ was fairly uniform with a range between 6.14 (NK2) and 7.71 (SK1). The bulk properties of the soil samples were broadly consistent across the whole sampling area.

\section{Taxonomic classification}

In total, about 428,968 raw sequence reads of the $16 \mathrm{~S}$ rRNA gene were acquired from the eight soil samples. Excluding the inferior quality chimeras and reads, about 403,421 clean reads where the average read length was 419 bp were applied to further analysis. The number of OTUs, as well as Shannon and Chaol indices, is listed in Table S1. The number of OTUs extracted from site NK2 was the highest (4718), in contrast to NK1 which was the lowest (1809). The results showed about $38.3 \%$ of total reads appeared once in the eight libraries. The correlation between OTUs of bacteria and different sites was shown in the co-occurrence networks (Fig. S1).

In total, approximately 30 phyla were identified in the soil samples. The difference in the abundance of classification groups is the main factor influencing the overall classification model. Most of these clean reads were related to Proteobacteria. Proteobacteria accounted for 36.2-83.2\% 
(mean 54.1\%) in the eight libraries and was more abundant in North ore zone (Fig. S1). Acidobacteria accounted for $36.2-83.2 \%$ of raw reads which were the second most abundant phylum. Bacteroidetes (2.4-12.9\%), unclassified (1.1-10.4\%) and Actinobacteria (1.3-12.3\%) were the third, fourth and fifth most abundant phyla, respectively. Planctomycetes $(0.3-11.3 \%)$ was the sixth most abundant phyla in all samples, except NK1 in which it was only $0.5 \%$. As shown in Fig. S2, Verrucomicrobia, Chloroflexi, Gemmatimonadetes, Firmicutes and Parcubacteria were the other abundant phyla.

The order of all abundant Classes including Betaproteobacteria, Alphaproteobacteria, Gammaproteobacteria, unclassified, Deltaproteobacteria, Actinobacteria and Acidobacteria-Gp6 are summarized in Fig. S2. Among Proteobacteria, Betaproteobacteria accounted for $18.8 \%$ of the total reads and was the most abundant class. Subsequently, Alphaproteobacteria, Gammaproteobacteria and Deltaproteobacteria accounted for $15.0 \%, 14.1 \%$ and $5.8 \%$, respectively. Betaproteobacteria and Gammaproteobacteria showed greater abundance in NK1, but lower in NK2.

The relative abundance of major phyla are shown in Fig. S3 and reflect the response of microbial community to geochemical conditions of each sample (Fig. 2). Different genera were enriched in the soil samples with "unclassified" as the most abundant in all soil samples (12.97-42.6\% of total valid reads in each sample). Specific genera could be identified with high abundance, but varied sample locations:

Escherichia/Shigella in SK1 (25.93\%); Sphingomonas in NK3 (8.83\%) and SK4 (10.93\%); Gp6 in NK2 (9.89\%), NK3(5.1\%) and SK4 (9.02\%). Thiobacillus in SK1 (7.23\%), SK2 $(8.72 \%)$ and SK3 (9.77\%). Pseudomonas in SK1 (9.31\%). Luteolibacter and Noviherbaspirillum in NK4 (6.24\%) and NK1(5.6\%).

The PCA highlighted the differences between microbial communities in the soil samples $(97 \%$ sequence similarity of OTUs) and showed that the microbial communities from South ore zone (SK1, SK2, SK3 and SK4) were clustered, while those from the North ore zone were remote from each other (Fig. 2). The highest abundant top ten species in the samples are shown in Fig. S4.

In order to determine the dominant bacterial taxonomic groups related to $\mathrm{Sb}$ concentration levels in the soil, the microbial communities in North ore and South ore zones were contrasted with Welch's t test, and the results are shown in Fig. S5. At the phylum level, the mean proportion of Verrucomicrobia, Chloroflexi, Parcubacteria, Gemmatimonadetes and Firmicutes show different levels; however, all $P$ values were greater than 0.05 . At genus level, the mean proportion of Bradyrhizobium, Hyphomicrobium, Thiobacillus and Aridibacter show different levels, and only for Bradyrhizobium is $P$ value lower than 0.05 . These finding suggest that there is no obvious difference in microbial

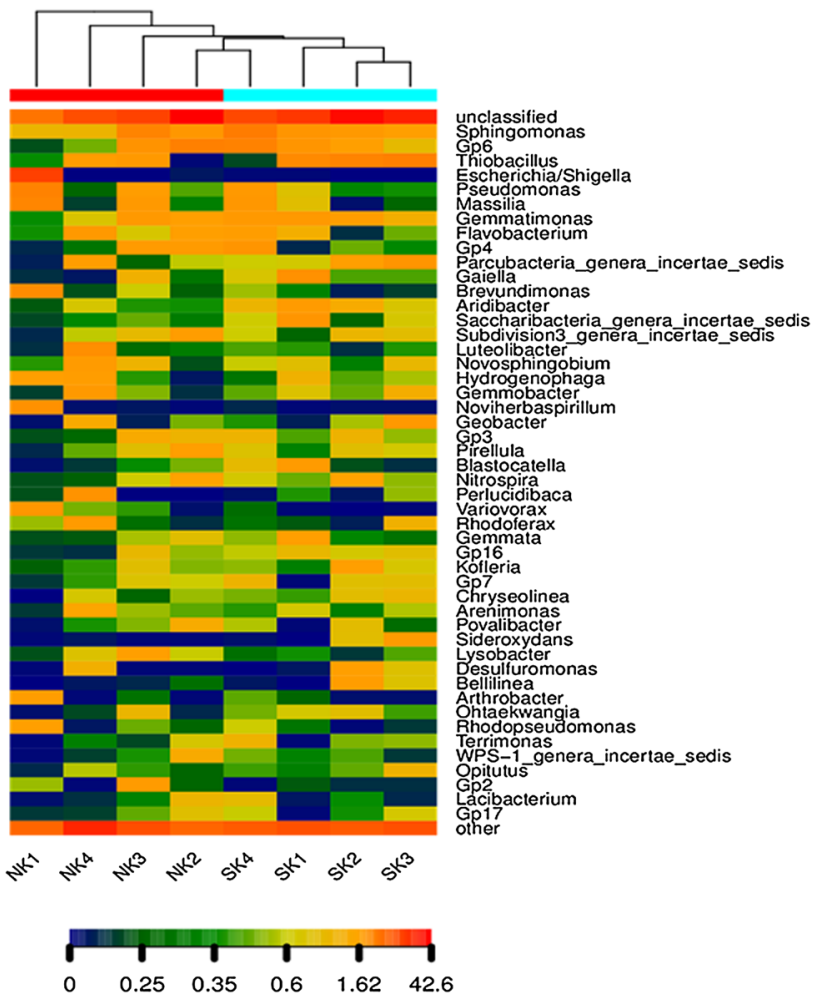

Fig. 2 Abundance of microbial genera with a relative abundance of more than $1 \%$ in at least one sequencing library from the samples collected across the site. The relative percentage of genera are represented by hue, and cluster analysis results showing grouping of sampling sites with SK1-3 clearly separate from the other locations

population structure between the north and south mining areas.

\section{Relationship of Microbial community and available toxic element fractions}

The heat map showing strength of correlation between species abundance and the relative availability of the individual elements in the study is shown in Fig. 3. Supplementary information contains a definition of the chemical fractions. We can identify three distinct associations between microbial and chemical responses:

1. Intolerance of the available fractions of all toxic elements (e.g., Gemmatimonas, Pirellula, Spartobacteria);

2. Good tolerance of mobile fractions of all elements (e.g., Povalibacter, Spartobacteria); and

3. A specific response showing tolerance of available $\mathrm{Sb}$, $\mathrm{Hg}$ and $\mathrm{Cd}$ and intolerance of $\mathrm{As}, \mathrm{Pb}$ (e.g., Escherichial Shigella and Arthrobacter) or the reverse (e.g., Gemmatimonas, Sphingomonas). 
Fig. 3 Spearman's rank correlation coefficients heat map and cluster analysis between available fractions of different toxic elements ( $\mathrm{Sb}, \mathrm{As}, \mathrm{Pb}, \mathrm{Cd}$ and $\mathrm{Hg}$ ) and the relative abundance of genus with relative abundance of more than $1 \%$ in at least one sequencing library. Different hue indicates different correlation coefficients. Abbreviations are shown in Table 1. *Significant correlations $(p<0.05)$; **significant correlations $(p<0.01)$

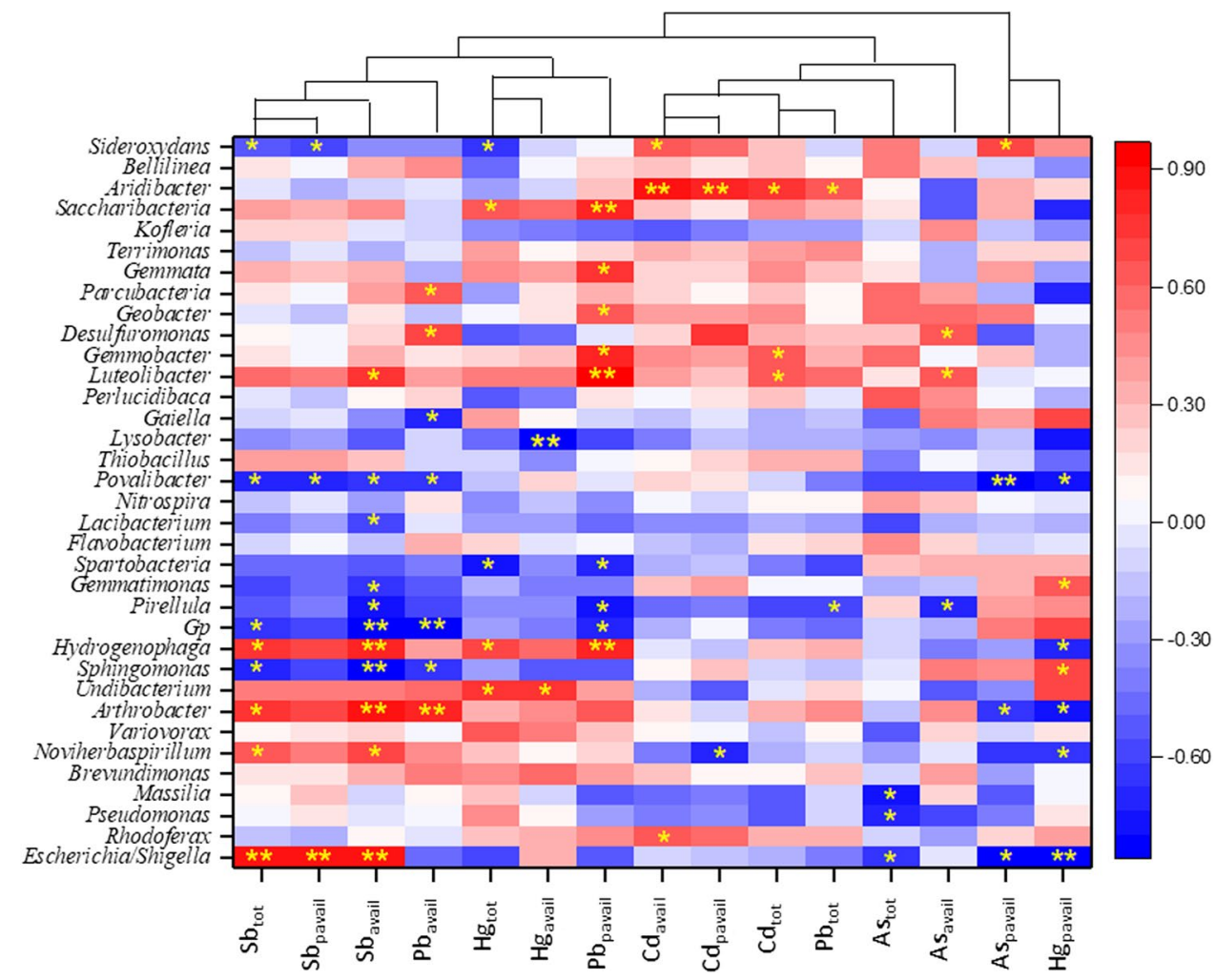

The broad classifications do not highlight any particular associations at the family level. The individual associations provide much more opportunity to understand potential metabolic relationships.

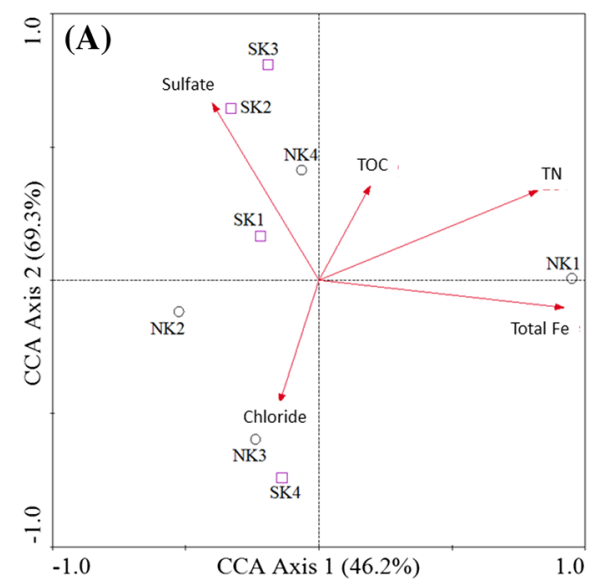

Fig. 4 The canonical correspondence analysis (CCA) of the correlation between bacterial libraries at each sample site (NK1-4, SK1-4) and (a) the broader soil geochemical parameters and (b) chemically available toxic element fractions defined by sequential chemical

\section{Relationship between the environment conditions and microbial communities}

Canonical correspondence analysis (CCA) was the best method to identify possible relationships between geochemical parameters and 16S rRNA gene data in soil samples (Fig. 4). Sulfate, total nitrogen and total Fe were closely associated with the structure of bacterial community

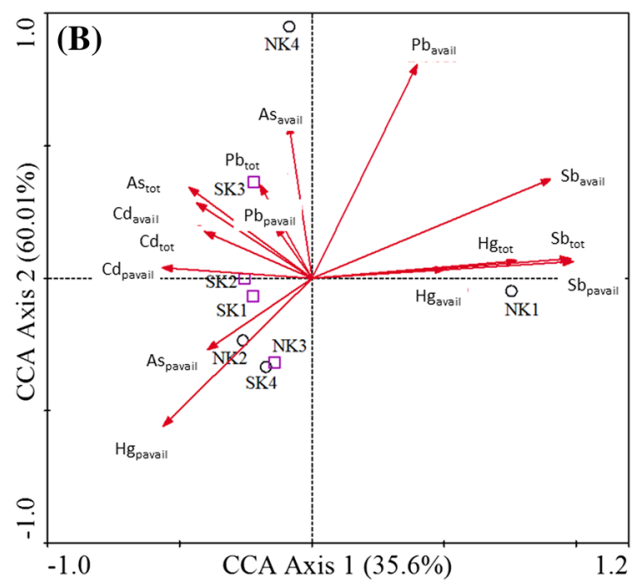

extraction (see abbreviations in Table 1 for definition of individual fractions). Plots highlight association of toxic elements with geochemical parameters such as " $\mathrm{S}$ " and isolation of $\mathrm{NK} 1$, reflecting the nature of ore processed at that location 
(Fig. 4a). There was positive correlation between microbial communities and $\mathrm{SO}_{4}{ }^{2-}$ as well as $\mathrm{Cl}^{-}$in libraries except for site NK1. This outlier may indeed reflect the varying ore mineralogy on the site, with the northern deposit extracting $\mathrm{Sb}$ associated with oxide mineral phases, additional elements more frequently hosted in sulfide

The relatively short length of total carbon vectors implied that there was no strong correlation between total carbon and community composition compared with other measured factors. There was positive correlation between factors of total nitrogen, total carbon, as well as total Fe and CCA axis 1; however, there was negative correlation between factors of $\mathrm{SO}_{4}{ }^{2-}$ and $\mathrm{Cl}^{-}$and $\mathrm{CCA}$ axis 1 (Fig. 4a). There was positive correlation between factors of $\mathrm{SO}_{4}{ }^{2-}$, total carbon as well as total nitrogen and CCA axis 2, but total $\mathrm{Fe}$ and $\mathrm{Cl}^{-}$were negatively correlated with CCA axis 2 in this study.

The CCA highlighted that $\mathrm{SO}_{4}{ }^{2-}$ had a significant impact on the microbial communities, which corresponds with previous research (Xiao et al. 2016). The content of $\mathrm{SO}_{4}{ }^{2-}$ in soil will affect all microbial communities by dominating the distribution of sulfate-reducing bacteria (SRB). The abundance of SRB was linearly related to the content of $\mathrm{SO}_{4}{ }^{2-}$ in soil samples. For instance, Desulfuromonas was more abundant at NK4 and SK2 which had relatively high content of $\mathrm{SO}_{4}{ }^{2-}$. In addition, because the soil samples came from surface horizons, the SRB have lower abundance compared to those found in other studies (Sun et al. 2016a, b; Xiao et al. 2016). It has also been reported that SRB can transform As and other transition metals (Barton et al. 2015). Since Sb and As have similar chemistry and toxicity and they often co-occur in natural deposits (Terry et al. 2015), we speculate that these SRB may participate in the bioconversion cycle of antimony.

The element and compounds of Fe have been identified as important environmental parameters for evaluating the microbial communities (Fig. 4a). The elevated concentrations of Fe in soil can promote the growth of iron-metabolizing bacteria (Xiao et al. 2016). Although the abundance of Fe was not particularly high in the soil samples in this study, the total Fe did increase at the NK1, NK3 and NK4 sampling points. These three soil samples also displayed high relative abundances of Hydrogenophaga (Wang et al. 2014) and Sideroxydans (Lu et al. 2017) which are considered as Fe(II)-oxidizing bacteria. Rhodoferax ferrireducens with the function of Fe(III) reduction (Gault et al. 2011) was also detected in the soil. Thus, we could not exclude that circulation of $\mathrm{Fe}$ in soil may coincide with the circulation of $\mathrm{Sb}$ as well as $\mathrm{As}, \mathrm{Pb}, \mathrm{Hg}$ and $\mathrm{Cd}$.

The formation of microbial community structure is closely related to the concentration of total carbon and total nitrogen in soil (Cookson et al. 2005; Wang et al. 2014; Xiao et al. 2016). In this study, Fig. 4a shows that total nitrogen and total carbon were positively related to the communities present. Different proportions of total nitrogen and total carbon can alter the abundance and structure of heterotrophic microorganisms, including Pseudomonas, Anaerolinea and Dechloromonas, which can degrade organic matter (Sun et al. 2015).

\section{Relationship between toxic element contamination and bacterial taxa}

From results shown in Table 1 , most of the $\mathrm{Sb}, \mathrm{As}, \mathrm{Pb}, \mathrm{Cd}$ and $\mathrm{Hg}$ are associated with inert fractions of each metal. The effects of various fractions of the toxic elements on the total microbial community and individual bacterial groups can be elucidated from the results of CCA, Welch's $t$ test, and Spearman's rank correlations. As CCA demonstrated, obvious correlation existed between different fractions of $\mathrm{Sb}$ in soils and the overall microbial communities. The extractable fractions of PTEs, including $\mathrm{Sb}_{\text {tot }}, \mathrm{Sb}_{\text {avail }}$, $\mathrm{Sb}_{\text {pavail }}, \mathrm{Pb}_{\text {avail }}, \mathrm{Hg}_{\text {pavail }}, \mathrm{Hg}_{\text {tot }}$ and $\mathrm{As}_{\text {avail }}$, had strong correlation with the community composition as demonstrated by the length of their corresponding vectors, while the impact of $\mathrm{Pb}_{\text {pavail }}, \mathrm{Cd}_{\text {tot }}$ and $\mathrm{As}_{\text {pavail }}$ was weaker (Fig. 4b). In addition, all microbial communities except for those from NK1 were negatively correlated with the absolute concentrations of $\mathrm{Sb}_{\text {tot }}, \mathrm{Sb}_{\text {avail }}, \mathrm{Sb}_{\text {pavail }}, \mathrm{Hg}_{\text {tot }}, \mathrm{Hg}_{\text {avail }}$ and $\mathrm{Pb}_{\text {avail }}$. Desulfuromonas (genus), Thiobacillus (order) and Aridibacter (order) had relatively high abundance in soil more strongly contaminated with $\mathrm{Sb}, \mathrm{As}, \mathrm{Pb}, \mathrm{Cd}$ and $\mathrm{Hg}$. The $\mathrm{SRB}$ abundance in this study was lower than that in other studies (Sun et al. 2016a, b; Xiao et al. 2016), reflecting the fact that several samples from this study were derived from aerobic environments compared to the prevalence of studies in anaerobic systems. The Spearman rank correlation implied associations between different forms of $\mathrm{Sb}, \mathrm{As}, \mathrm{Pb}, \mathrm{Cd}$ and $\mathrm{Hg}$ and bacterial taxa. As shown in Fig. 3, significant correlations were found between Escherichia/Shigella and all forms of $\mathrm{Sb}$, implying a significant positive correlation between total $\mathrm{Sb}$ and this genus. But it was negatively correlated with As, $\mathrm{Pb}, \mathrm{Cd}$ and $\mathrm{Hg}$ forms. Escherichia was enriched in NK1 with relative abundances of $25.93 \%$. It is unclear whether Escherichia can reduce or oxidize $\mathrm{Sb}$ and $\mathrm{As}$, but this genus exhibits resistance and ability to survive in Sb-rich soil (Terry et al. 2015; Sun et al. 2016a, b); however, this species was not found in other samples.

Pseudomonas occurs widely in various metal-contaminated soils (Kozdrój and van Elsas 2001; Nguyen et al. 2018; Shi et al. 2013). Notably, Pseudomonas sp. had significant correlation with $\mathrm{Sb}_{\text {avail }}$ and $\mathrm{As}_{\text {avail }}$, while it was uncorrelated with other forms. Pseudomonas sp. was enriched in NK1 $(9.31 \%)$ and relatively high in SK1 and SK4. Pseudomonas sp. can execute autotrophic and heterotrophic reduction of various metals simultaneously (Amde et al. 2017), such as $\mathrm{Pb}$ and $\mathrm{Cd}$. Pseudomonas sp. are metabolically diverse and 
can use other electron acceptors, such as $\mathrm{Sb}(\mathrm{V})$ and $\mathrm{As}(\mathrm{V})$ (Lai et al. 2016; Nguyen et al. 2018), which may explain the enrichment of Pseudomonas in the environments where $\mathrm{Sb}$, $\mathrm{As}, \mathrm{Pb}$ and $\mathrm{Hg}$ co-occur, and we can therefore confirm the potential role of Pseudomonas sp. in enzymatic $\mathrm{Sb}$ and $\mathrm{As}$ reduction. Geobacter has been identified as $\mathrm{Sb}(\mathrm{V})$-reducing cultures (Zhu et al. 2018) and may be a key performer in the As redox cycle (Hu et al. 2019). Also, Geobacter can reduce $\mathrm{Sb}(\mathrm{V})$ by using micro-molecular organics as electron donors. Soils in this study contained low organic matter, and there were adverse redox conditions, which may both explain the low abundance of Geobacter in all sites. High-valent metal reduction combined with organic compound oxidation by microorganisms has been widely reported (Methé et al. 2003), and Pseudomonas and Geobacter may possess great potential for bioremediation of sites with co-contamination of $\mathrm{Sb}, \mathrm{As}, \mathrm{Pb}, \mathrm{Cd}$ and $\mathrm{Hg}$ (Sun et al. 2016b).

There was a positive correlation between Noviherbaspirillum and $\mathrm{Sb}_{\text {tot }}$ as well as $\mathrm{Sb}_{\text {avail }}$, while it was negatively correlated with both $\mathrm{Cd}_{\text {pavail }}$ and $\mathrm{Hg}_{\text {pavail }}$. Noviherbaspirillum was enriched in NK1 (5.6\%) and demonstrated relatively higher abundances in NK2 and NK3. However, there are no previous studies relating to Noviherbaspirillum with $\mathrm{Sb}$ or As resistance and cycling, highlighting our limited knowledge on microbial metabolism of co-contaminants $\mathrm{Sb}$, As, $\mathrm{Pb}, \mathrm{Cd}$ and $\mathrm{Hg}$.

Arthrobacter was positively correlated with $\mathrm{Sb}_{\text {tot }}(p$ $<0.05), \mathrm{Sb}_{\text {avail }}(p<0.05)$ and $\mathrm{Pb}_{\text {avail }}(p<0.05)$, while it was negatively correlated with $\mathrm{As}_{\text {pbioavail }}$ as well as $\mathrm{Hg}_{\text {pavail }}$, which identified Arthrobacter as a core microorganism in the soils contaminated by $\mathrm{Sb}$ and As (Sun et al. 2017). It was previously isolated from $\mathrm{Pb}$-contaminated and $\mathrm{Cd}$-contaminated soil and was not dependent on the concentration of metals in soils (Kozdrój and van Elsas 2001). In addition, Arthrobacter can oxidize compounds such as ammonia nitrogen and pesticide. The findings implied that Arthrobacter spp. had a metabolic versatility for different electron donors, displaying their potential role to reduce $\mathrm{As}(\mathrm{V})$ and $\mathrm{Sb}(\mathrm{V})$ in the environment, which is consistent with other work (Shi et al. 2013). However, there was no significant correlation between Arthrobacter and poorly available forms (especially for the Fe-Mn oxides fraction) in this work. The observation of these dynamic microbial communities hosted in extremely contaminated sites showed strong correlations between many taxonomic groups and the different available fractions of $\mathrm{Sb}$, As and $\mathrm{Hg}$, implying that some microorganisms may be involved in the biogeochemical circulation of $\mathrm{Sb}$ and As.

These metabolic cycles are likely to hold great potential for bioremediation in a range of contaminated environments and that we provide a locally focused basis for a generic approach to screen sites providing a diagnostic tool to characterize the inherent microbial potential for remediation of toxic element contaminated sites.

We found that both Sphingomonas and Gp4 are negatively correlated with $\mathrm{As}, \mathrm{Pb}, \mathrm{Cd}$ and $\mathrm{Hg}$ forms, except $\mathrm{Hg}_{\text {pavail }}$ and $\mathrm{As}_{\text {pavail }}$. The relative abundance of Sphingomonas was enriched in all sites (1.17-10.93\%), indicating Sphingomonas occurred widely in the XKS Sb mine. Because of the unique environment here, it has not been found in other $\mathrm{Sb}$ mines, such as the Dushan $\mathrm{Sb}$ mine in Guizhou, central South China (Sun et al. 2016a; Xiao et al. 2016b; Xiao et al. 2017). Sphingomonas contains oxidizing species, which can oxidize As (III) and Sb (III) (Shi et al. 2013). The relative abundance of $G p$ (including Gpl 16), which was identified as Acidobacteria phylum, was a frequently detected genus in this study, ranging from 0.5 to $16.69 \%$ of the total reads of bacteria. The relatively high abundances of the $G p$-related bacteria in all sites suggest that it was the main taxonomic group in this study area. Also the strain GP could reduce $\mathrm{Pd}(\mathrm{II})$ and $\mathrm{Au}(\mathrm{III})$ to $\mathrm{Pd}(0)$ and $\mathrm{Au}(0)$ (Zhang and $\mathrm{Hu} 2018)$. Although Gp4 was found by (Xiao et al. 2017) in the Sb-contaminated soil, no one has reported that this genus is responsible for biological circulation of $\mathrm{Sb}$ or As, reflecting our insufficient knowledge of As and $\mathrm{Sb}$ microbiology.

Hydrogenophaga was considered as the key participants in the redox circulation of As (Hu et al. 2019). Hydrogenophaga which contains As(III)-oxidizing strains of Hydrogenophaga sp. str. NT-14 (Van den Hoven and Santini 2004) was frequently isolated from As-rich and Sbrich sediment, and it was observed to oxidize As(III) as well as Sb(III) (Ghosh et al. 2014; Hu et al. 2019; Terry et al. 2015). In addition, when As and Sb coexist in soil, Hydrogenophaga oxidize As prior to $\mathrm{Sb}$ (Ghosh et al. 2014; Terry et al. 2015). However, Hydrogenophaga was positively correlated with most $\mathrm{Sb}$ fractions, especially with $\mathrm{Sb}_{\text {avail }}(p<0.01)$, while it was uncorrelated with most As fractions. The correlation between the forms of $\mathrm{Sb}$ and As and this genus probably reflects that the content of $\mathrm{Sb}$ was generally higher than that of other toxic elements in this study area. Furthermore, Hydrogenophaga was also positively correlated with $\mathrm{Hg}_{\text {tot }}$ and $\mathrm{Pb}_{\text {pavail }}$. This may imply that some common enzymes such as Arx and Aio are involved in the oxidation of different toxic elements and may be formed during chemoautotrophy based on $\mathrm{Sb}(\mathrm{III})$. However, further work needs to be done to confirm this.

It is worth noting that Povalibacter is negatively correlated with $\mathrm{Pb}_{\text {bavail }}, \mathrm{As}_{\text {pavail }}, \mathrm{Hg}_{\text {pavail }}$ and all $\mathrm{Sb}$ fractions. This result indicated that Povalibacter may show resistance to or participate in cycling these toxic elements. Unfortunately, no reports exist demonstrating the capability of Povalibacter for cycling of $\mathrm{Sb}, \mathrm{As}, \mathrm{Pb}, \mathrm{Cd}$ and $\mathrm{Hg}$, reflecting our limited knowledge on their metabolism. Further work such as gene 
mutation is required to investigate the exact role of these bacteria in soil.

The relative abundance of Thiobacillus was enriched in SK1 (7.23\%) and SK2 (8.72\%) and demonstrated relatively lower abundances in other sites. However, significant correlations between Thiobacillus and any metal forms were not observed in this study. The Thiobacillus was isolated in strongly acidic acid mine drainage environments and was also detected in As-rich and Sb-rich soils and sediments (Sun et al. 2016a, b; Xiao et al. 2016, 2017). Thiobacillus possess $\mathrm{Sb}$ resistance operon and can oxidize $\mathrm{Sb}_{2} \mathrm{~S}_{3}$ to $\mathrm{Sb}$ (III) or $\mathrm{Sb}$ (III) to $\mathrm{Sb}$ (v), which may explain the high abundance of Thiobacillus spp. in environments with coexisting $\mathrm{Sb}$ and As. Because $\mathrm{Sb}$ and As have similar chemical properties and toxicity and they often co-occur (Terry et al. 2015), Thiobacillus spp. may have the ability to oxidize As(III).

These specific relationships provide a strategy to enable optimization of conditions for bioremediation steps to be optimized.

\section{Conclusion}

The relationship between toxic elements and the microbial communities in soil from the XKS antimony highlighted that both the specific forms of toxic elements $\left(\mathrm{Sb}_{\text {tot }}, \mathrm{Sb}_{\text {avail }}\right.$, $\mathrm{Sb}_{\text {pavail }}, \mathrm{Pb}_{\text {avail }}, \mathrm{Hg}_{\text {pavail }}, \mathrm{Hg}_{\text {tot }}$ and $\left.\mathrm{As}_{\text {avail }}\right)$ and overall control by local geochemical conditions $\left(\mathrm{SO}_{4}{ }^{2-}\right.$, Total $\mathrm{Fe}$ and total nitrogen) determine the overall population structure. Associations have been identified between taxonomic groups which are tolerant or intolerant to available chemical fractions and others which were chemically more sensitive. There was positive correlation between the abundance of several bacterial taxonomic groups including Hydrogenophaga, Thiobacillus, Geobacter, Arthrobacter, Pseudomonas as well as Aridibacter and high levels of available toxic elements. The microbial diversity within the site is dominated by Gramnegative organisms (many with rod (bacillus) morphologies but also some filamentous forms) and with a wide range of metabolic capabilities (anaerobes, e.g., Saccharibacteria, metal oxidizing, e.g., Geobacter, chemoautotrophs, e.g., Gemmata, sulfate reducing, e.g., Desulfuromonas). These results provide a framework to develop site relevant, optimal remediation approaches based upon, e.g., bio-stimulation or bio-augmentation of soil matrices, for example exploring potential of Arthrobacter and Escherichia/Shigella in Sb cycling, particularly controlling site wide runoff and dispersal in local aquatic systems.

Acknowledgements This study was financially supported by the National Natural Science Foundation of China (No. 41672350), the
Natural Science Foundation of Hunan Province (No. 2016JJ6041) and Chinese Postdoctoral Science Foundation (No. 2018M632961).

\section{Compliance with ethical standards}

Human and animal rights This article does not contain any studies with human participants or animals performed by any of the authors.

Open Access This article is licensed under a Creative Commons Attribution 4.0 International License, which permits use, sharing, adaptation, distribution and reproduction in any medium or format, as long as you give appropriate credit to the original author(s) and the source, provide a link to the Creative Commons licence, and indicate if changes were made. The images or other third party material in this article are included in the article's Creative Commons licence, unless indicated otherwise in a credit line to the material. If material is not included in the article's Creative Commons licence and your intended use is not permitted by statutory regulation or exceeds the permitted use, you will need to obtain permission directly from the copyright holder. To view a copy of this licence, visit http://creativecommons.org/licenses/by/4.0/.

\section{References}

Ainsworth N, Cooke JA, Johnson MS (1990) Distribution of antimony in contaminated grassland: 1 -vegetation and soils. Environ Pollut 65:65-77. https://doi.org/10.1016/0269-7491(90)90165-9

Amde M, Liu J, Tan Z, Bekana D (2017) Transformation and bioavailability of metal oxide nanoparticles in aquatic and terrestrial environments. A review. Environ Pollut 230:250-267. https://doi. org/10.1016/j.envpol.2017.06.064

ATSDR (2017) ATSDR's substance priority list, 2017, agency for toxic substances \& disease registry, https://www.atsdr.cdc.gov/ spl/\#2017spl last Accessed 13/12/2019

ATSDR (2019) Toxicological profile for antimony, agency for toxic substances \& disease registry, updated 26 September 2019, (https ://www.atsdr.cdc.gov/ToxProfiles/tp.asp?id=332\&tid=58) last accessed 13/12/2019

Bacon JR, Davidson CM (2008) Is there a future for sequential chemical extraction? The Analyst 133:25-46. https://doi.org/10.1039/ b711896a

Barton LL, Tomei-Torres FA, Xu H, Zocco T (2015). Metabolism of metals and metalloids by the sulfate-reducing bacteria. In: Saffarini D (ed), Bacteria-Metal Interactions. Springer, Gewerbestrasse, pp 57-83 https://doi.org/10.1007/978-3-319-18570-5_4

Buanuam J, Wennrich R (2010) Dynamic flow-through sequential extraction for assessment of fractional transformation and interelement associations of arsenic in stabilized soil and sludge. $\mathrm{J}$ Hazard Mater 184:849-854. https://doi.org/10.1016/j.jhazm at.2010.08.119

Caporaso JG, Kuczynski J, Stombaugh J, Al E (2010) QIIME allows analysis of high-throughput community sequencing data. Nat Methods 7:335-336. https://doi.org/10.1038/nmeth.f.303

Chen J, Fan W, Sun R, Sun R (2007) Bioavailability and species distribution of heavy metals in sewage-irrigated soil from Xinhe. Acta Sci Circum 27:831-837

Cookson WR, Abaye DA, Marschner P, Murphy DV, Stockdale EA, Goulding KWT (2005) The contribution of soil organic matter fractions to carbon and nitrogen mineralization and microbial community size and structure. Soil Biol Biochem 37:1726-1737. https://doi.org/10.1016/j.soilbio.2005.02.007 
Escudero LB, Quintas PY, Wuilloud RG, Dotto GL (2019) Recent advances on elemental biosorption. Environ Chem Lett 17:409_ 427. https://doi.org/10.1007/s10311-018-0816-6

Filella M, Belzile N, Lett M-C (2007) Antimony in the environment: a review focused on natural waters.III. Microbiota relevant interactions. Earth-Sci Rev 80:195-217. https://doi.org/10.1016/j.earsc irev.2006.09.003

Flynn HC, Meharg AA, Bowyer PK, Paton GI (2003) Antimony bioavailability in mine soils. Environ Pollut 124:93-100. https://doi. org/10.1016/s0269-7491(02)00411-6

Gal J, Hursthouse AS, Cuthbert SJ (2006) Chemical availability of arsenic and antimony in industrial soils. Environ Chem Lett 3:149-153. https://doi.org/10.1007/s10311-005-0022-1

Gault AG, Ibrahim A, Langley S, Renaud R, Takahashi Y, Boothman C, Lloyd JR, Clark ID, Ferris FG, Fortin D (2011) Microbial and geochemical features suggest iron redox cycling within bacteriogenic iron oxide-rich sediments. Chem Geol 281:41-51. https:// doi.org/10.1016/j.chemgeo.2010.11.027

Gebel T (1997) Arsenic and antimony: comparative approach on mechanistic toxicology. Chem Biol Interact 107:131-144. https ://doi.org/10.1016/s0009-2797(97)00087-2

Ghosh D, Bhadury P, Routh J (2014) Diversity of arsenite oxidizing bacterial communities in arsenic-rich deltaic aquifers in West Bengal, India. Front Microbiol 5:1-14

Guo X, Wang K, He M, Liu Z, Yang H, Li S (2014) Antimony smelting process generating solid wastes and dust: characterization and leaching behaviors. J Environ Sci 26:1549-1556. https:// doi.org/10.1016/j.jes.2014.05.022

Guo W, Fu Z, Wang H, Song F, Wu F, Giesy JP (2018) Environmental geochemical and spatial/temporal behavior of total and speciation of antimony in typical contaminated aquatic environment from Xikuangshan, China. Microchem J 137:181-189. https://doi.org/10.3389/fmicb.2014.00602

He M, Wang X, Wu F, Fu Z (2012) Antimony pollution in China. Sci Total Environ 421-422:41-50. https://doi.org/10.1016/j.scito tenv.2011.06.009

Hu M, Sun W, Krumins V, Li F (2019) Arsenic contamination influences microbial community structure and putative arsenic metabolism gene abundance in iron plaque on paddy rice root. Sci Total Environ 649:405-412. https://doi.org/10.1016/j.scito tenv.2018.08.388

Kozdrój J, van Elsas JD (2001) Structural diversity of microbial communities in arable soils of a heavily industrialised area determined by PCR-DGGE fingerprinting and FAME profiling. Appl Soil Ecol 17:31-42. https://doi.org/10.1016/s0929 -1393(00)00130-X

Lai C, Wen L, Zhang Y, Luo S, Wang Q, Luo Y, Chen R, Yang X, Rittmann B, Zhao H (2016) Autotrophic antimonate bio-reduction using hydrogen as the electron donor. Water Res 88:467-474. https://doi.org/10.1016/j.watres.2015.10.042

Lee P, Yu S (2016) Lead isotopes combined with a sequential extraction procedure for source apportionment in the dry deposition of Asian dust and non-Asian dust. Environ Pollut 210:65-75. https ://doi.org/10.1016/j.envpol.2015.12.010

Lepš J, Šmilauer P (2003) Multivariate analysis of ecological data using CANOCO: using the Canoco for windows 4.5 package. Cambridge University press, Cambridge

Lu Y, Xu L, Shu W, Zhou J, Chen X, Xu Y, Qian G (2017) Microbial mediated iron redox cycling in Fe (hydr)oxides for nitrite removal. Biores Technol 224:34-40. https://doi.org/10.1016/j. biortech.2016.10.025

Luo J, Bai Y, Liang J, Qu J (2014) Metagenomic approach reveals variation of microbes with arsenic and antimony metabolism genes from highly contaminated soil. PLoS ONE 9:e108185. https://doi. org/10.1371/journal.pone.0108185
Magalhaes D, Marques MR, Baptista DF, Buss DF (2015) Metal bioavailability and toxicity in freshwaters. Environ Chem Lett 13:6987. https://doi.org/10.1007/s10311-015-0491-9

Methé BA, Nelson KE, Eisen JA, Paulsen IT, Nelson W, Heidelberg JF, Wu D, Wu M, Ward N, Beanan MJ, Dodson RJ, Madupu R, Brinkac LM, Daugherty SC, Deboy RT, Durkin AS, Gwinn M, Kolonay JF, Sullivan SA, Haft DH, Selengut J, Davidsen TM, Zafar N, White O, Tran B, Romero C, Forberger HA, Weidman J, Khouri H, Feldblyum TV, Utterback TR, Van Aken SE, Lovley DR, Fraser CM (2003) Genome of geobacter sulfurreducens: metal reduction in subsurface environments. Science 302:19671969. https://doi.org/10.1126/science. 1088727

Mo C, Wu F, Fu Z, Zhu J, Ran L (2013) Antimony, arsenic and mercury pollution in agricultural soil of antimony mine area in Xikuangshan, Hunan. Acta Mineral Sinica 33:344-350

Nguyen VK, Choi W, Park Y, Yu J, Lee T (2018) Characterization of diversified $\mathrm{Sb}(\mathrm{V})$-reducing bacterial communities by various organic or inorganic electron donors. Biores Technol 250:239 246. https://doi.org/10.1016/j.biortech.2017.11.044

Okkenhaug G, Zhu Y-G, Luo L, Lei M, Li X, Mulder J (2011) Distribution, speciation and availability of antimony $(\mathrm{Sb})$ in soils and terrestrial plants from an active Sb mining area. Environ Pollut 159:2427-2434. https://doi.org/10.1016/j.envpol.2011.06.028

Okkenhaug G, Gebhardt KAG, Amstaetter K, Bue HL, Herzel H, Mariussen E, Almås ÅR, Cornelissen G, Breedveld GD, Rasmussen $\mathrm{G}$ (2016) Antimony $(\mathrm{Sb})$ and lead $(\mathrm{Pb})$ in contaminated shooting range soils: $\mathrm{Sb}$ and $\mathrm{Pb}$ mobility and immobilization by iron based sorbents, a field study. J Hazard Mater 307:336-343. https://doi. org/10.1016/j.jhazmat.2016.01.005

Ollson CJ, Smith E, Herde P, Juhasz AL (2017) Influence of sample matrix on the bioavailability of arsenic, cadmium and lead during co-contaminant exposure. Sci Total Environ 595:660-665. https ://doi.org/10.1016/j.scitotenv.2017.04.036

Pan Y, Yang G (1988) Soil background value and its research in Hunan province. China Environmental Science Press, Beijing

Park J, Kim S, Ahn JS, Lim D, Han Y (2018) Mobility of multiple heavy metalloids in contaminated soil under various redox conditions: effects of iron sulfide presence and phosphate competition. Chemosphere 197:344-352. https://doi.org/10.1016/j.chemospher e.2018.01.065

Quast C, Pruesse E, Yilmaz P et al (2013) The SILVA ribosomal RNA gene database project: improved data processing and web-based tools. Nucleic Acids Res 4:590-596. https://doi.org/10.1093/nar/ gks1219

Schloss PD, Westcott SL, Ryabin T et al (2009) Introducing mothur: open-source, platform-independent, community-supported software for describing and comparing microbial communities. Appl Environ Microbiol 75:7537-7541. https://doi.org/10.1128/ aem.01541-09

Shi Z, Cao Z, Qin D, Zhu W, Wang Q, Li M, Wang G (2013) Correlation models between environmental factors and bacterial resistance to antimony and copper. PLoS ONE 8:e78533. https://doi. org/10.1371/journal.pone.0078533

Sun W, Li Y, Lora RM, Luo S, Huang W, Lee JK, Mack EE, Max M, Donna EF (2015) Identification of anaerobic aniline-degrading bacteria at a contaminated industrial site. Environ Sci Technol 49:11079-11088. https://doi.org/10.1021/acs.est.5b02166

Sun W, Xiao E, Dong Y, Tang S, Krumins V, Ning Z, Sun M, Zhao Y, Wu S, Xiao T (2016a) Profiling microbial community in a watershed heavily contaminated by an active antimony ( $\mathrm{Sb}$ ) mine in Southwest China. Sci Total Environ 550:297-308. https://doi. org/10.1016/j.scitotenv.2016.01.090

Sun W, Xiao E, Kalin M, Krumins V, Dong Y, Ning Z, Liu T, Sun M, Zhao Y, Wu S, Mao J, Xiao T (2016b) Remediation of antimony-rich mine waters: assessment of antimony removal and shifts in the microbial community of an onsite field-scale 
bioreactor. Environ Pollut 215:213-222. https://doi.org/10.1021/ acs.est. 8 b03853

Sun W, Xiao E, Xiao T, Krumins V, Wang Q, Haggblom MM, Dong Y, Tang S, Hu M, Li B (2017) Response of soil microbial communities to elevated antimony and arsenic contamination indicates the relationship between the innate microbiota and contaminant fractions. Environ Sci Technol 51:9165. https://doi.org/10.1021/ acs.est.7b00294

Sun W, Xiao E, Häggblom M, Krumins V, Dong Y, Sun X, Li F, Wang Q, Li B, Yan B (2018) Bacterial survival strategies in an alkaline tailing site and the physiological mechanisms of dominant phylotypes as revealed by metagenomic analyses. Environ Sci Technol 52:13370-13380

Telford K, Maher W, Krikowa F, Foster S, Ellwood MJ, Ashley PM, Lockwood PV, Wilson SC (2009) Bioaccumulation of antimony and arsenic in a highly contaminated stream adjacent to the Hillgrove Mine, NSW, Australia. Environ Chem 6:133-143. https:// doi.org/10.1071/en08097

Terry LR, Kulp TR, Wiatrowski H, Miller LG, Oremland RS (2015) Microbiological oxidation of antimony(III) with oxygen or nitrate by bacteria isolated from contaminated mine sediments. Appl Environ Microbiol 81:8477-8488. https://doi.org/10.1128/ aem.01970-15

Tessier A, Campbell PGC, Bisson M (1979) Sequential extraction procedure for the speciation of particulate trace metals. Anal Chem 51:844-851. https://doi.org/10.1021/ac50043a017

Ungureanu G, Santos S, Boaventura R, Botelho C (2015) Arsenic and antimony in water and wastewater: overview of removal techniques with special reference to latest advances in adsorption. J Environ Manage 151:326-342. https://doi.org/10.1016/j.jenvm an.2014.12.051

Van den Hoven RN, Santini JM (2004) Arsenite oxidation by the heterotroph hydrogenophaga sp. str. NT-14: the arsenite oxidase and its physiological electron acceptor. BBA-Bioenerg 1656:148-155. https://doi.org/10.1016/j.bbabio.2004.03.001

Wang Q, Garrity GM, Tiedje JM, Cole JR (2007) Naïve Bayesian classifier for rapid assignment of rRNA sequences into the new bacterial taxonomy. Appl Environ Microbiol 73:5261-5267. https://doi. org/10.1128/aem.00062-07

Wang X, He M, Xi J, Lu X (2011) Antimony distribution and mobility in rivers around the world's largest antimony mine of
Xikuangshan, Hunan province, China. Microchem J 97:4-11. https://doi.org/10.1016/j.microc.2010.05.011

Wang H, Hu C, Zhang L, Li X, Zhang Y, Yang M (2014) Effects of microbial redox cycling of iron on cast iron pipe corrosion in drinking water distribution systems. Water Res 65:362-370. https ://doi.org/10.1016/j.watres.2014.07.042

Wei J, Bai R, Yu Q, Yao J (2010) Speciation and distribution of Cr in hardened cement paste_-modified Tessier sequential extraction procedures. J Chinese Ceram Soc 38:1167-1172

Wenzel WW, Kirchbaumer N, Prohaska T, Stingeder G, Lombi E, Adriano DC (2001) Arsenic fractionation in soils using an improved sequential extraction procedure. Anal Chim Acta 436:309-323. https://doi.org/10.1016/s0003-2670(01)00924-2

Xiao E, Krumins V, Tang S, Xiao T, Ning Z, Lan X, Sun W (2016) Correlating microbial community profiles with geochemical conditions in a watershed heavily contaminated by an antimony tailing pond. Environ Pollut 215:141-153. https://doi.org/10.1016/j. envpol.2016.04.087

Xiao E, Krumins V, Xiao T, Dong Y, Tang S, Ning Z, Huang Z, Sun W (2017) Depth-resolved microbial community analyses in two contrasting soil cores contaminated by antimony and arsenic. Environ Pollut 221:244-255. https://doi.org/10.1016/j.envpol.2016.11.071

Zhang H, Hu X (2018) Biosynthesis of Pd and Au as nanoparticles by a marine bacterium Bacillus sp. GP and their enhanced catalytic performance using metal oxides for 4-nitrophenol reduction. Enzyme Microb Technol 113:59-66. https://doi.org/10.1016/j. enzmictec.2018.03.002

Zhu X, Yao J, Wang F, Yuan Z, Liu J, Jordan G, Knudsen TŠ, Avdalović J (2018) Combined effects of antimony and sodium diethyldithiocarbamate on soil microbial activity and speciation change of heavy metals. Implications for contaminated lands hazardous material pollution in nonferrous metal mining areas. J Hazard Mater 349:160-167. https://doi.org/10.1016/j.jhazm at.2018.01.044

Publisher's Note Springer Nature remains neutral with regard to jurisdictional claims in published maps and institutional affiliations. 